\title{
Impact of emission trading and renewable energy support scheme on the optimality of generator side bidding
}

\author{
$A$ Arya, SPS Mathur and $M$ Dubey \\ Electrical Engineering Department, MANIT Bhopal, India
}

\begin{abstract}
As a major Green House Gases (GHG) producer, $\mathrm{CO}_{2}$ in particular, the electricity industry's emissions have turned in to a matter of immense concern in many countries, especially in India. India's economy and fast economic development has attracts the attention of the world. Emission trading schemes (ETS) and renewable energy support schemes (RESS) are implemented by the various developed countries to alleviate the affect of GHG emissions. In this paper, an optimization based market simulation approach is proposed with the consideration of emission trading schemes and renewable support schemes. To simulate the bidding strategy and for profit maximization, a particle swarm optimization (PSO) algorithm is used. As above problem is a multi-objective optimization problem, Where, in the first level each Genco submit the bid to the independent system operator and in the next level a optimization method is used for the determination of optimal bidding with the implementation of emission trading schemes and renewable support schemes. It is assumed that each generator should submit bid as a price taker's in sealed auction based on pay-as-bid market clearing price mechanism. The practicability of proposed optimization method is checked by an IEEE-30 bus test system consists of six suppliers.
\end{abstract}

\section{Introduction}

Energy market experienced a reformation process worldwide and market competition is transformed significantly from oligopoly to antagonistic market. The key endeavour of the energy market is to set up a competing market by minimizing the total production cost contingent on technical and practical constraints [1, 2]. The reformation started around mid-1980's in the various countries of the world. The pioneer of restructuring is the Chile, where it is started in 1987 [3]. Electric power industry reforms started in India after the enactment of Electricity act 2003, National electricity policy and Tariff policy. Two power exchanges i.e. Power Exchange India Ltd (PXIL) and Indian Energy Exchange ltd. (IEX) are in operation in India since 2008. The aspiration of reformation is to change the economics of energy market from monopoly to competing market, increased fuel availability and to develop new technologies to cater the aggressive market [4]. In a competitive energy market, all the price takers has market power and can make the healthy profit via its strategic bidding practices. Theoretically, to maximize the profit price takers should bid at very close to their marginal cost in the aggressive energy market and when a price takers attempt this, then this behaviour is called strategic bidding $[5,6]$. Consumer and customers are the two main parts of the company participating in the energy market. They all submit the bid for trading the electricity and for this purpose a bidding model is developed i.e. single side bidding or double side bidding. When all the entities submit their bid, marketer draws an aggregated supply/demand curve. The intersecting point of the above curve is called equilibrium point and it helps to find the market clearing price $[7,8]$.

According to different market mechanism and bidding protocolsvariousmodelling techniques have been presented by many researchers. These modelling techniques can be categorised as Optimization models, Game theory models, agent-based simulation models, and hybrid models [9, 10]. For the profit maximization of single participant, optimization model will be used and when rival's profit behaviour taken in to consideration then equilibrium model preferably used. The complexity of electricity market using agents gaming behaviour is obtained through the simulation model [11]. Many researchers present various papers based on these models $[12,13]$.

As a major Green House Gases (GHG) producer, $\mathrm{CO}_{2}$ in particular, the electricity industry's emissions have become an issue of extensive concern in many countries, especially in India whose emerging economy and rapid economic development has caught the attention of the world. Currently, India is the third largest greenhouse gas (GHG) emitter accounting for $6.65 \%$ of the global emissions and is projected to witness an increase of over $85 \%$ by 2030 under a business-as-usual scenario. India's energy consumption, over the last two decades almost tripled from 241 million tons of oil equivalent (Mtoe) in 1996 to 723.9 Mtoe in 2016 at a compounded annual growth rate (CAGR) of $5.4 \% . \mathrm{CO}_{2}$ emissions from 
electricity increased by about 50\% during 2005-2013 as electricity demand has grown and fossil fuels have remained the dominant source for generation. These emission values may increase appreciably in future as there are 315 new coal-based power plants proposed to come online by 2030 . Hence, this paper considers the impact of emission trading schemes and renewable support scheme on the optimal bidding of price takers in a restructured electricity market.

This paper is organized as, in section II, a mathematical model for estimating the price of the $\mathrm{CO}_{2}$ emission allowances is described and represented as stochastic optimization problem. Section III presented a computational procedure of PSO algorithm for the solution of optimal bidding in a competitive electricity market. Section IV depicts the execution of the proposed method with numerical simulation. Finally, Section V concludes the paper with possible directions for future research.

\section{Mathematical Formulation}

According to various countries, the formation of energy market primarily consist the spot market, medium and long term trade market which are suitable for practical purpose. Assume a power exchange operates in a day-ahead market and ISO check the system security and stabilization for the better operating condition. For the demand side bidding power exchange consists of $\mathrm{M}$ generating companies and $\mathrm{N}$ load customers submitting a nondecreasing demand function for the trading time slot $\mathrm{t} \varepsilon \mathrm{T}=(1,2 \ldots \ldots 24)$. If trading time slot assume as $30 \mathrm{~min}$ then $\mathrm{T}=48$. M generating companies includes thermal power station submit nondecreasing supply curve. In the day-ahead market, all the Genco's need to propose a bidding curve for the next operating day.

Under ETS, price takers (agent) require purchasing of $\mathrm{CO}_{2}$ emission allowances from the trading market with price $\mathrm{p}_{\mathrm{co} 2}$, then production cost function and marginal cost function of the agent (i) can be represented by the following equation.

$C_{i}\left(P_{t, i}\right)=\left(b_{i}+p_{c o_{2}} \eta_{i}\right) P_{t, i}+0.5 c_{i} P_{t, i}^{2}$

$M_{i}\left(P_{t, i}\right)=\left(b_{i}+p_{c o_{2}} \eta_{i}\right)+c_{i} P_{t, i}$

where, $\mathrm{C}_{\mathrm{i}}\left(\mathrm{q}_{\mathrm{t}, \mathrm{i}}\right)$ - Production cost of gencoi including $\mathrm{CO}_{2}$ emission. $\mathrm{M}_{\mathrm{i}}\left(\mathrm{q}_{\mathrm{t}, \mathrm{i}}\right)$ - Marginal cost of gencoi; $\mathrm{b}_{\mathrm{i}}, \mathrm{c}_{\mathrm{i}}$ Production cost constant coefficient; $\mathrm{q}_{\mathrm{t}, \mathrm{i}}$ - Output of gencoi at hour $\mathrm{t}$ and $\eta_{\mathrm{i}}-\mathrm{CO}_{2}$ emission factor.

$\mathrm{CO}_{2}$ emission allowances are depend on the consumed amount of fuel and can be expressed by the following equation.

$$
\epsilon_{G i}^{c o_{2}}=\frac{8760 * c_{\text {fuel }}}{\eta_{T} * L H V_{\text {fuel }}} * q_{G}
$$

where $c_{\text {fuel }}$ is the fuel input price, $\eta_{\mathrm{T}}$ is the thermodynamic efficiency of the plant and $\mathrm{LHV}_{\text {fuel }}$ is the fuel lower heating value (Mcal $/ \mathrm{kg})$.
If agent $\mathrm{i}$ select $\mathrm{j}^{\text {th }}$ strategy, then the equivalent constant represents as

$$
T_{j}=T_{\min }+\frac{j}{K-1}\left(T_{\max }-T_{\min }\right)
$$

Here $T_{\min }$ is the minimum value of constant $\mathrm{T}$ and $\mathrm{T}_{\max }$ is the maximum value of constant $\mathrm{T}$.

Thus the bidding price of agent $\mathrm{i}$ can be represented as

$$
B_{i}\left(P_{t, i}\right)=\alpha_{i}+p_{\mathrm{Co}_{2}} \eta_{i}+T_{j} \beta_{i} P_{t, i}
$$

Here the bidding problem is a bi-level optimization problem. Hence firstly, price takers possess the random samplings of $\alpha_{\mathrm{i}}$ and $\beta_{\mathrm{i}}$ according to their probability density function (pdf's), and in the second level profit maximization is achieved by using optimization technique.

Assuming that RESS adopts the feed-in tariffs mechanism, that is, all renewable energy would be purchased at a guaranteed premium price prenewable. The market clearing process of non-renewable energy in the market at hour $\mathrm{t}$ can be described as:

$$
\begin{aligned}
& b_{i}+p_{c 0_{2}} \eta_{i}+D_{i} c_{i} P_{t, i}=R_{t} \\
& \sum_{i=1}^{n} P_{t, i}=L_{t}-p_{\text {renewable }, t} \\
& x_{t, i} P_{t, \text { min }} \leq P_{t, i} \leq x_{t, i} P_{t, \text { max }}
\end{aligned}
$$

where $\mathrm{R}_{\mathrm{t}}$ is the MCP at hour $\mathrm{t} ; \mathrm{n}$ is the number of the agents in the market; $\mathrm{T}$ is the number of hours over the studied time horizon; $\mathrm{L}_{\mathrm{t}}$ is the forecasted load at hour $\mathrm{t}$; $P_{\text {renewable, }}$ is the forecasted renewable energy at hour $t ; x_{t, j}$ represents the operation state of Genco $i$ at hour $t$ (1: operation; 0: down); $\mathrm{P}_{\text {imax }}$ and $\mathrm{P}_{\mathrm{imin}}$ are the upper and lower output limits of Genco i.

For $\mathrm{i}^{\text {th }}$ price takers for $\mathrm{t}^{\text {th }}$ hour in the day-ahead market, profit maximization function can be represented as:

$$
F\left(\alpha_{i}, \beta_{i}\right)=R \times P_{t, i}-C_{i}\left(P_{t, i}\right)
$$

From equation (7), our objective is to evaluate $\alpha_{\mathrm{i}}$ and $\beta_{\mathrm{i}}$ for maximization the profit subject to some inequality constraints. Price takers do not have access to complete information of their opponent, so it is required for price takers to estimate other participant's unknown information

\section{Proposed Method based on PSO}

Genetic algorithm (GA) and Particle swarm optimization (PSO) have been successfully applied to solve the various engineering optimization problem efficiently. However, both the algorithms have strengths and weaknesses[14]. Thus keeping the advantages of PSO algorithms into account, the main objective of this work is to develop an efficient technique to find the optimal solution of the bidding strategy problems.

Particle swarm optimization technique was first proposed by the James Kennedy and Russell C. Eberhart in 1995 to model the collective behaviours of swarm flocking [14]. It is an efficient population-based stochastic algorithm for intelligent search and optimization.For the different engineering design problems various alternatives of the PSO algorithm were suggested but the most effective one is introduced by Shi and Eberhart [15] - [17]. PSO consist of two populations 
(i.e. pbest, gbest). pbest is regarded as a candidate solution in the search space and gbest is used to guide the former's update. In PSO each swarm have many particles with their updated own position and flight velocity, which can represents a potential solution (i.e. individual). In PSO system, each swarm associated with two properties(i.e. position vectors, velocity vectors). Mathematically, a particle keeps updating their velocity and position evaluated by the following formula:

$$
\begin{gathered}
v_{j d}(t+1)=\omega * v_{j d}(t)+c_{1} * r_{1} *\left[p_{b e s t}(t)-x_{j d}(t)\right] \\
+c_{2} * r_{2} *\left[g_{b e s t}(t)-x_{j d}(t)\right]
\end{gathered}
$$

$x_{j d}(t+1)=x_{j d}(t)+v_{j d}(t+1)$

Where $v_{j d}(\mathrm{t}+1)=\left[\mathrm{v}_{\mathrm{j} 1}, \mathrm{v}_{\mathrm{j} 2}, \mathrm{v}_{\mathrm{j} 3}, \ldots . \mathrm{v}_{\mathrm{ji}}, \ldots \mathrm{v}_{\mathrm{jd}}\right]$ is the updated particle velocity for $\mathrm{j}^{\text {th }}$ particle in $\mathrm{i}^{\text {th }}$ dimension. $x_{j d}(\mathrm{t}+1)$ $=\left[\mathrm{x}_{\mathrm{j} 1}, \mathrm{x}_{\mathrm{j} 2}, \mathrm{x}_{\mathrm{j} 3}, \ldots . \mathrm{x}_{\mathrm{ji}}, \ldots \mathrm{x}_{\mathrm{jd}}\right]$ is the updated position of the $\mathrm{j}^{\text {th }}$ particle in $\mathrm{i}^{\text {th }}$ dimension. $\mathrm{c}_{1} * r_{1}$ and $c_{2} * r_{2}$ are the random acceleration coefficient number in the interval $\left[0, \mathrm{c}_{1}\right]$ and $\left[0, c_{2}\right]$ respectively, which reflect the weight of accelerated particle towards pest and g $\mathrm{g}_{\text {best }}$ respectively. $\omega$ is the inertial dampener to balancing the global and local search. p best $_{\text {is }}$ the previous best position of the $\mathrm{j}^{\text {th }}$ particle and $g_{b e s t}$ is the global best position of the whole swarm[15],[16].

The step by step procedure to obtain the maximize profit using particle swarm optimization technique is presented as follows:

Step 1: Initialization

(a) Generate random population of profit $F\left(\alpha_{i}\right.$, $\beta_{\mathrm{i}}$ ).

(b) Read system data: Generator data (cost coefficients, generator limits), aggregate load, price elasticity, $\mathrm{K}, \mathrm{D}_{\min }, \mathrm{D}_{\max }$ and emission factor.

Step 2: Evaluate generator output for each supplier.

(a) Check generator output with their output limits.

(b) Add all generators.

Step 3: Evaluate fitness function $\mathrm{F}(\mathrm{X})$ using equation (5.12)

Step 4: Comparison of fitness function with $p_{\text {best }}$ and $g_{\text {best }}$.

(a) Check $p_{\text {best }} \leq F(X)$, then update $p_{\text {best }}=X$.

(b) Check g $g_{\text {best }} \leq$ p $_{\text {best }}$, then update $g_{\text {best }}=$ pbest.

Step 5: Update the velocity \& position of each individuals using equation (9) \& (10) respectively.

Step 6: Repeat from step 3 to 6, until iteration reaches to their maximum limits. Return the best fitness (maximum profit) computed at maximum iteration as a global fitness.

Step 7: Print the optimum value of profit, c.p.u. time and plot graph between iteration versus \% error.

$\%$ Error $=\frac{\text { Generation }- \text { Demand }}{\text { Demand }} \times 100$
It is obvious that for maximizing the benefit of a supplier, bidding coefficients $\alpha_{\mathrm{i}}$ and $\beta_{\mathrm{i}}$ cannot be selected independently. So, one coefficient can be fixed and other can be determined by the optimization technique.

The flow chart diagram of the standard particle swarm optimization is shown in Fig.1.

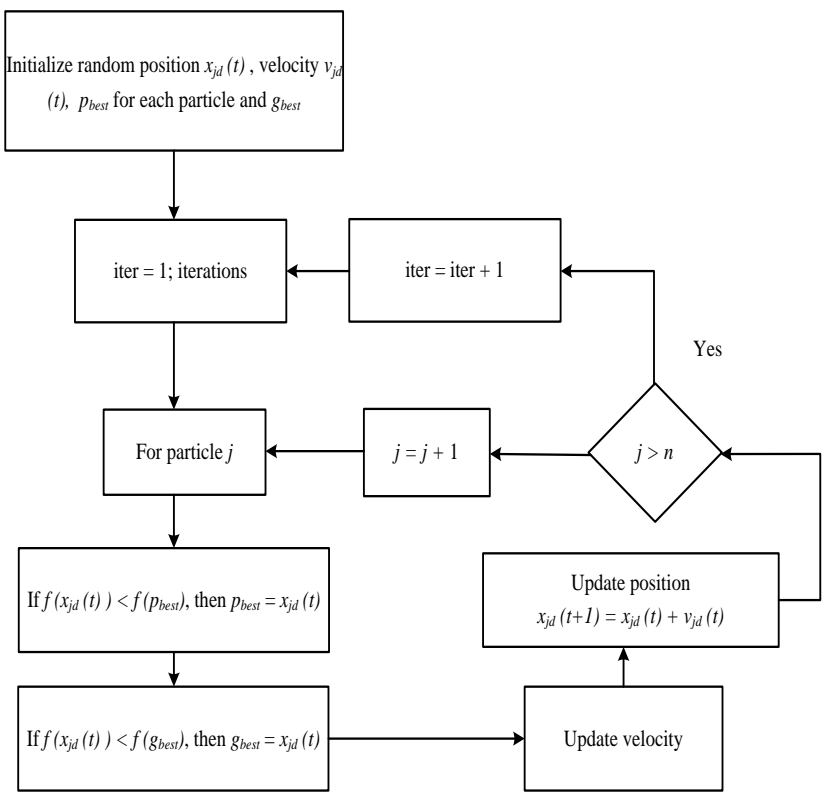

Fig.1.Flow Chart of Standard PSO [16]

The flow chart for obtaining bidding coefficient $\beta_{\mathrm{i}}$ using PSO is shown in Fig.2.

\section{Results using proposed method based on PSO}

In this paper PSO method has been used to evaluate the optimal bidding strategy of price takers with carbon emission trading, for this purpose an IEEE-30 bus system is considered. In the proposed methodology, problem is represented as a bi-level optimization problem. It is assumed that each price makers should submit bid in sealed auction based on pay-as-bid MCP mechanism with knowing the rival's bidding behaviour. The IEEE-30 bus system consists of six price takers which are participate in a day-ahead energy market and assume each possesses one generation unit. Also assume that five are of coalfired ones, and sixth is a CCGT one. The characteristics of price takers, unit constraints, cost coefficients and $\mathrm{CO}_{2}$ emission factors and generation output limits of IEEE-30 bus system are listed in Table I [18]. 


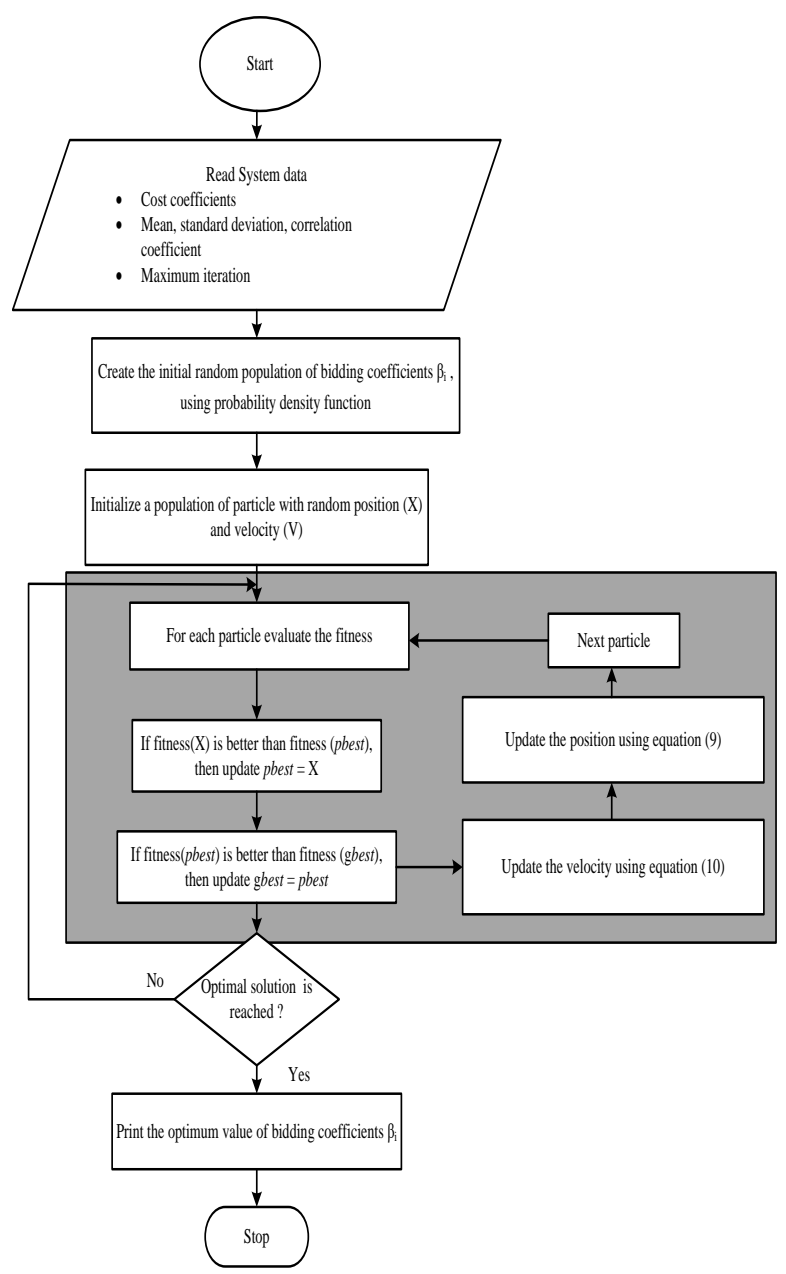

Fig.2. Flow chart for obtaining bidding coefficient $\beta$ i using PSO

Table 1.Cost coefficients, generator output limits and emission factor of price takers

\begin{tabular}{|l|c|c|c|c|c|c|}
\hline $\begin{array}{c}\text { Gen. } \\
\text { No. }\end{array}$ & $\mathrm{a}_{\mathrm{i}}$ & $\mathrm{b}_{\mathrm{i}}$ & $\mathrm{c}_{\mathrm{i}}$ & $\begin{array}{c}\mathrm{P}_{\mathrm{t}, \mathrm{max}} \\
(\mathrm{MW})\end{array}$ & $\begin{array}{c}\mathrm{P}_{\mathrm{t}, \mathrm{min}} \\
(\mathrm{MW})\end{array}$ & $\eta_{\mathrm{i}}$ \\
\hline 1. & 0.00375 & 2.0 & 0 & 200 & 50 & 0.918 \\
\hline 2. & 0.01750 & 1.7 & 0 & 80 & 20 & 0.937 \\
\hline 3. & 0.06250 & 1.0 & 0 & 50 & 15 & 1.025 \\
\hline 4. & 0.00834 & 3.2 & 0 & 35 & 10 & 0.958 \\
\hline 5. & 0.02500 & 3.0 & 0 & 30 & 10 & 1.125 \\
\hline 6. & 0.02500 & 3.0 & 0 & 40 & 12 & 0.426 \\
\hline
\end{tabular}

For the execution of the proposed methodology, the position of each particle is modified by position updating process in which the value of parameter $\omega, c_{1}, c_{2}$ and $c_{3}$ should determine in advance. Assumed the value of $\omega_{\max }$, $\omega_{\min }$ and iter $_{\max }$ are 1.0, 0.1 and 100 respectively. The constant parameters associated with PSO and modifiedGA is presented in Table 2:
Table 2.Assumptions made by different methods

\begin{tabular}{|c|c|}
\hline PSO & Modified-GA [19] \\
\hline No. of particles = 100; & $\mathrm{P}=100 ; \mathrm{m}=20 ;$ \\
$\mathrm{m}=20 ;$ max. iteration & generation $=100 ; \quad \mathrm{Pe}_{\mathrm{e}}$ \\
$=100 ; \mathrm{c}_{1}, \mathrm{c}_{2}=2.0 ;$ & $=0.15 ; \mathrm{P}_{\mathrm{c}}=0.85: \mathrm{P}_{\mathrm{m}}=$ \\
$\omega=0.9-0.4$ & 0.005 \\
\hline
\end{tabular}

To solve Bidding strategy problem, methodology developed for PSO program has been carried out on Intel(R) Core(TM) i7-3770 $3.40 \mathrm{GHz}$ PC with a 4GB RAM (in MATLAB 2013a). This software provide an interactive approach for solving optimal bidding strategy problem with carbon emission trading in dealing with generation output/input limits, bidding coefficients and emission allowances.

Optimal bidding strategy of generators has been developed for the following two cases:

Case - I: without considering the impact of carbon emission allowances.

Case - II: with considering the impact of carbon emission allowances

Case - I:In this case, when the impact of carbon emission allowances is not considered, assume $\mathrm{Q}_{0}=300$ with coefficient of price elasticity $\mathrm{k}=5$. Here bidding problem is a bi-level optimization problem. In the first level, generators possess the random samplings of $\alpha_{i}$ and $\beta_{\mathrm{i}}$ according to their pdf's (Probability density function), and in the second level profit maximization is achieved by using optimization technique.

For the random sampling assumes that the generators fix $\alpha_{\mathrm{i}}=\mathrm{b}_{\mathrm{i}}$ and a PSO method is used to evaluate $\beta_{\mathrm{i}}$. $\beta_{\mathrm{i}}$, should not be less than $a_{i}$ and it is searched between $a_{i}$ and $\mathrm{M} \times \mathrm{a}_{\mathrm{i}}$ and $\mathrm{M}=10$ for all simulations.

The optimal bid price $\left(\beta_{\mathrm{i}}\right)$, market clearing price (MCP), generation output and expected profit of generators, without considering the impact of carbon emission allowances by using proposed method with symmetrical information of rival's are presented in Table 3 and Table 4.. Fig. 3 shows the variation of profit of each generator for the proposed PSO, Modified-GA and Monte carlo method.

Table 3.Optimal bidding coefficient $\left(\beta_{\mathrm{i}}\right)$

\begin{tabular}{|c|c|c|c|}
\hline Generators & PSO & Modified-GA [19] & $\begin{array}{c}\text { Monte carlo } \\
{[20]}\end{array}$ \\
\hline 1 & 0.0114 & 0.01580 & 0.0254 \\
\hline 2 & 0.0488 & 0.0510 & 0.1261 \\
\hline 3 & 0.1741 & 0.1823 & 0.2347 \\
\hline 4 & 0.0232 & 0.0242 & 0.0284 \\
\hline 5 & 0.0670 & 0.0728 & 0.1043 \\
\hline 6 & 0.0670 & 0.0728 & 0.1261 \\
\hline
\end{tabular}


Table 4. Optimal bidding strategies for IEEE-30 bus system without considering the carbon emission allowances.

\begin{tabular}{|c|c|c|c|c|c|c|}
\hline \multirow{2}{*}{$\begin{array}{l}\text { Genera } \\
\text { tors }\end{array}$} & \multicolumn{2}{|c|}{ PSO } & \multicolumn{2}{|c|}{$\begin{array}{c}\text { Modified-GA } \\
{[19]}\end{array}$} & \multicolumn{2}{|c|}{$\begin{array}{l}\text { Monte } \\
\text { carlo [20] }\end{array}$} \\
\hline & $\begin{array}{l}\mathrm{P}_{\mathrm{j}}(\mathrm{M} \\
\mathrm{W})\end{array}$ & $\begin{array}{l}\text { Profit } \\
(\$)\end{array}$ & $\begin{array}{l}\mathrm{P}_{\mathrm{j}}(\mathrm{M} \\
\mathrm{W})\end{array}$ & $\begin{array}{l}\text { Profit } \\
\text { (\$) }\end{array}$ & $\begin{array}{l}P_{j} \\
(M \\
W)\end{array}$ & $\begin{array}{l}\text { Profit } \\
\text { (\$) }\end{array}$ \\
\hline 1 & 140 & 500.2 & 140 & 425.2 & 140 & 352.4 \\
\hline 2 & 72.5 & 245.7 & 70 & 202.8 & 68 & 152.6 \\
\hline 3 & 26.4 & 135.4 & 25.6 & 124.2 & 22 & 95.85 \\
\hline 4 & 20.8 & 105.6 & 20 & 95.2 & 20 & 68.1 \\
\hline 5 & 28.5 & 132.5 & 25 & 115.6 & 25 & 95.6 \\
\hline 6 & 28.5 & 132.5 & 25 & 115.6 & 25 & 95.6 \\
\hline $\begin{array}{c}\text { MCP } \\
\text { (\$/MW } \\
\mathrm{h})\end{array}$ & \multicolumn{2}{|c|}{7.25} & \multicolumn{2}{|c|}{5.85} & \multicolumn{2}{|c|}{4.25} \\
\hline $\begin{array}{c}\text { Total } \\
\text { Profit } \\
(\$)\end{array}$ & \multicolumn{2}{|c|}{1251.9} & \multicolumn{2}{|c|}{1078.6} & \multicolumn{2}{|c|}{860.15} \\
\hline
\end{tabular}

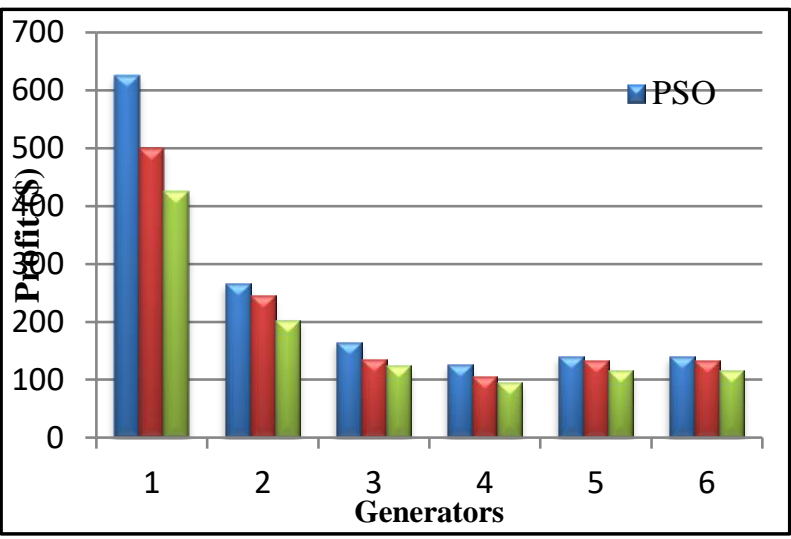

Fig.3.Profit of each generator using above approaches for IEEE30 bus test system incase -I

Case - II: Assume that the $\mathrm{CO}_{2}$ emission allowances is 5 million tons in the emission market after applying the emission reduction commitment for one year (365 days) and assume the upper limit of $\mathrm{CO}_{2}$ emission allowance price is $20 \$$ ton. Also, Set $K=5, D_{\min }=1$ and $D_{\max }=2$.

Market clearing price (MCP), generation output and expected profit of generators, with considering the impact of carbon emission allowances by using proposed method with symmetrical information of rival's are presented in Table 5.

After analyzing CCGT unit from the above results it is clear shown that, with considering carbon emission trading, proposed method gives lesser values of the bidding coefficients than PSO and GA method. Thereby increasing the dispatched power, market clearing price, expected profit and the actual profit. Hence the power output of power producers using hybrid method are more than other approaches presented here.
Table 5. Optimal bidding strategies for IEEE-30 bus system with considering the carbon emission allowances.

\begin{tabular}{|c|c|c|c|c|c|c|}
\hline \multirow{2}{*}{$\begin{array}{c}\text { Generato } \\
\text { rs }\end{array}$} & \multicolumn{2}{|c|}{ PSO } & \multicolumn{2}{|c|}{$\begin{array}{c}\text { Modified-GA } \\
{[19]}\end{array}$} & \multicolumn{2}{|c|}{$\begin{array}{c}\text { Monte Carlo } \\
{[20]}\end{array}$} \\
\hline & $\begin{array}{c}\mathrm{P}_{\mathrm{j}}(\mathrm{M} \\
\mathrm{W})\end{array}$ & $\begin{array}{l}\text { Profit } \\
(\$)\end{array}$ & $\begin{array}{c}\mathrm{P}_{\mathrm{j}}(\mathrm{M} \\
\mathrm{W})\end{array}$ & $\begin{array}{c}\text { Prof } \\
\text { it } \\
(\$)\end{array}$ & $\begin{array}{c}\mathrm{P}_{\mathrm{j}}(\mathrm{M} \\
\mathrm{W})\end{array}$ & $\begin{array}{c}\text { Profit } \\
(\$)\end{array}$ \\
\hline 1 & 200 & $\begin{array}{c}952.3 \\
6\end{array}$ & 190 & $\begin{array}{c}650 . \\
5\end{array}$ & 180.5 & 558.6 \\
\hline 2 & 78.5 & 385.6 & 76.2 & $\begin{array}{c}250 . \\
4\end{array}$ & 75 & 195.4 \\
\hline 3 & 36.24 & 278.2 & 36.85 & $\begin{array}{c}164 . \\
5\end{array}$ & 32.5 & $\begin{array}{c}112.4 \\
2\end{array}$ \\
\hline 4 & 35 & 250.4 & 35 & $\begin{array}{c}145 . \\
8\end{array}$ & 35 & 125.8 \\
\hline 5 & 28.5 & 237.8 & 30 & $\begin{array}{c}139 . \\
2\end{array}$ & 30 & $\begin{array}{c}105.6 \\
5\end{array}$ \\
\hline 6 & 28.5 & 237.8 & 30 & $\begin{array}{c}139 . \\
2\end{array}$ & 30 & $\begin{array}{c}105.6 \\
5\end{array}$ \\
\hline $\begin{array}{c}\text { MCP } \\
(\$ / \mathrm{MWh} \\
)\end{array}$ & \multicolumn{2}{|c|}{7.65} & \multicolumn{2}{|c|}{6.80} & \multicolumn{2}{|c|}{5.25} \\
\hline $\begin{array}{c}\text { Total } \\
\text { Profit }(\$)\end{array}$ & \multicolumn{2}{|c|}{2342.16} & \multicolumn{2}{|c|}{1489.6} & \multicolumn{2}{|c|}{1203.52} \\
\hline
\end{tabular}

In the case without the $\mathrm{CO}_{2}$ emission trading considered, the profit of GenCo 6 is $140.2 \$$ through strategic bidding in the day-ahead electricity market. However, when the $\mathrm{CO}_{2}$ emission trading is enforced, its profit reaches $365.4 \$$ representing 2.61 times of the former. This is mainly because that the enforcement of the $\mathrm{CO}_{2}$ emission trading has significantly improved the competitiveness of the CCGT unit. Fig.4 and Fig.5 shows the variation of profit of each generator and the convergence characteristics for the proposed PSO and Modified-GA method. From Fig.5 it is clearly seen that PSO method converged in 22 iterations while ModifiedGA method converged in 28 iterations. So, PSO method has better, faster and precise convergence.

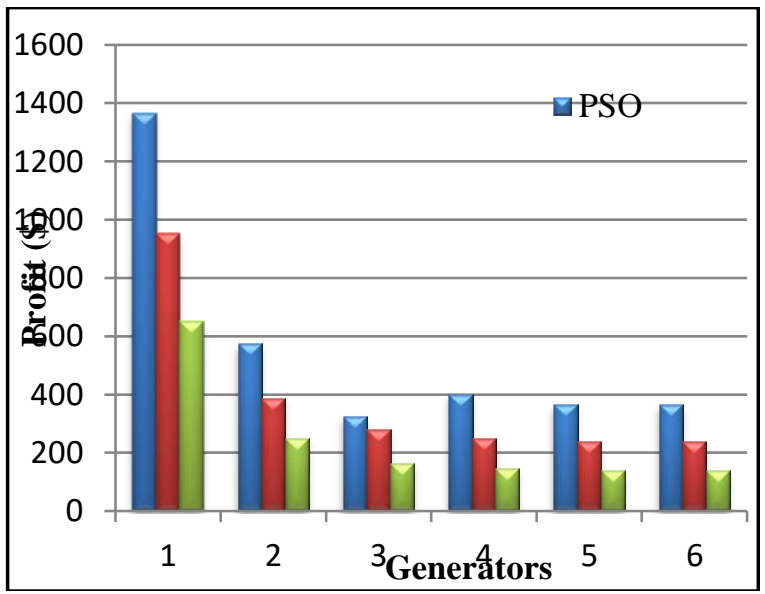

Fig. 4. Profit of each generator using above approaches for IEEE-30 bus test system with considering the carbon emission allowances and RESS 


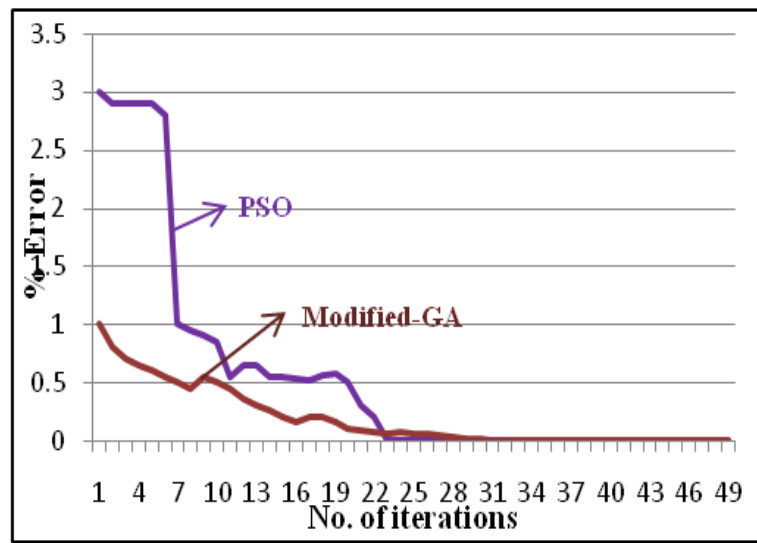

Fig.5.Convergence characteristic for IEEE-30 bus test system

\section{Conclusion}

In this paper, the impact of the emission trading and renewable energy support schemes on the development of optimal bidding strategies for generation companies participating in a day-ahead electricity market is investigated. Emission trading mainly has impact on electricity price and thus, indirect effect on consumption and investment. Emissions trading in general increase the price of electricity, which in turns leads to less electricity consumption. In long run it leads to an investment shift in favour of renewable energy sources. A mathematical model has been developed for estimating the price of $\mathrm{CO}_{2}$ emission allowances, and for building the optimal bidding strategies for generation companies and represented as a stochastic bi-level optimization problem. The main objectives of proposed methodology are: i) to consider bi-level optimization model with the impact of $\mathrm{CO}_{2}$ emission trading and renewable support scheme on optimal bidding, ii) uses a PSO method to solve optimization problem. The PSO method gives the best solution quality, reduced computation time and maximizes profit for optimal bidding strategy. In the further research, proposed model can be enhanced by taking the demand response program and arbitrage policies in to account.

This publication is an outcome of the $\mathrm{R} \& \mathrm{D}$ work undertaken in the project under the Young Faculty Research Fellowship, Visvesvaraya $\mathrm{PhD}$ scheme of Ministry of Electronics \& Information Technology, Government of India, being implemented by Digital India Corporation (formerly Media Lab Asia).

We would also like to show our gratitude to Maulana Azad National Institute of Technology, Bhopal, India for providing us the required facilities during the course of this research.

\section{References}

1. D. Kirschen, G. Strbac, Fundamentals of Power System Economics, University of Manchester Institute of Science and Technology, John Wiley \& Sons, UK, 2004.
2. (Chapter 1-3) S. Stoft, Power System Economics (Designing Markets for Electricity), Part 1, IEEE Press \& Wiley, New York, NY, 2002.

3. Jamasb T., Thakur T., Bag B., "Smart electricity distribution networks, business models, and application for developing countries", 2018, Energy Policy 114, 22-29.

4. Youfei Liu, Felix F. Wu. "Generator bidding in oligopolistic electricity markets using optimal control: fundamentals and application". IEEE Transactions on Power Systems, vol. 21, no. 3, august 2006, pp 1050-61.

5. Shahdehpour M, Almoush M. Restructured Electrical Power Systems Operation, Trading and Volatility. Marcel Dekker, Inc.; 2001.

6. David AK, Wen F. Strategic bidding in competitive electricity markets: a literature survey. In: Proceedings of IEEE power engineering society summer meeting, vol. 4; 2000. p. 2168-73.

7. A.K. David, F. Wen, Market power in electricity supply, IEEE Trans. Energy Convers. 16 (No. 4) (2001) 352-360.

8. Kian Ashkan R, Cruz Jose B, Thomas Robert J. Bidding strategies in oligopolistic dynamic electricity double-sided auctions. IEEE Trans Power Syst 2005; 20(1):50-8.

9. Srivastava Anurag K, Kamalasadan Sukumar, Patel Daxa, Sankar Sandhya, Al- Olimat Khalid S. Electricity markets: an overview and comparative study. Int J Energy Sec Manage 2011; 5(2):169-200.

10. Shahidehpour M, Yamin H, Li Z. Market Operations in Electric Power Systems: Forecasting, Scheduling, and Risk Management. New York: IEEE Wiley-Inter Science; 2002.

11. Gong Li, Jing Shi, Xiuli Qu b, "Modeling methods for GenCo bidding strategy optimization in the liberalized electricity spot market - A state-of-the-art review" Energy 36 (2011) 4686-4700.

12. S. Mathur, A. Arya, M.Dubey, "Optimal bidding strategy for price takers and customers in a competitive electricity market", Cogent Engineering Taylor Francis online (2017) vol.1 issue 4, pp. 1-15.

13. S. Mathur, A. Arya, M.Dubey, "Impact of emission trading on optimal bidding of price takers in a competitive energy market" Advances in Intelligent System and computing, Springer (2018) Vol. 741, pp. 171-180.

14. J. Kennedy, R. Eberhart, Particle swarm optimization, in: Proc. IEEE Int. Conf. Neural Networks, IV, Perth, Australia, 1995, pp. 1942-1948.

15. Kumar A., Pant S., and Singh S.B., "Reliability Optimization of Complex System by Using Cuckoos Search algorithm" Mathematical Concepts and Applications in Mechanical Engineering and Mechatronics, IGI Global, 2016, 95-112

16. Pant S and Singh SB, "Particle swarm optimization to reliability optimization in complex system" In: IEEE international conference on quality and 
reliability, Bangkok, Thailand, Sept 14-17, 2011, pp 211-215.

17. Shi and R. Eberhart, "A modified particle swarm optimizer," In Proc. IEEE World Congr. Comput. Intell., 1998, pp. 69-73.

18. I. J. Raglend; N. P. Padhy, "Solutions to Practical Unit Commitment Problems with Operational, Power Flow and Environmental Constraints" IEEE Power Engineering Society General Meeting, 2006, pp. 1-8.

19. S. Soleymani, Bidding strategy of generation companies using PSO combined with SA method in the pay as bid markets, Int. J. Electr. Power Energy Syst. 33 (2011) 1272-1278.

20. A. Azadeh, S.F. Ghaderi, B. PourvalikhanNokhandan, M. Sheikhalishahi, A new genetic algorithm approach for optimizing bidding strategy viewpoint of profit maximization of a generation company, Expert Syst. Appl. 39 (No. 1) (2012) 1565-1574. 